\title{
In the Absence of Other Fc Receptors, FcyRIIIA Transmits a Phagocytic Signal That Requires the Cytoplasmic Domain of Its $\gamma$ Subunit
}

\author{
J.-G. Park, R. E. Isaacs, P. Chien, and A. D. Schreiber \\ University of Pennsylvania School of Medicine, Philadelphia, Pennsylvania 19104
}

\begin{abstract}
The transmembrane isoform of FcrRIII, FcrRIIIA, is found on NK cells, cultured monocytes, and tissue macrophages in association with a dimer of an accessory subunit, either $\gamma$ or $\zeta$. Functions of individual Fc receptors have been difficult to analyze due to coexpression of the receptors on hematopoietic cells and permanent cell lines expressing Fc receptors. cDNAs for the $\alpha$ and $\gamma$ subunits of Fc $\gamma$ RIIIA were cotransfected into COS-1 cells, which lack endogenous Fc receptors, to evaluate receptormediated phagocytosis and changes in $\left[\mathrm{Ca}^{2+}\right]_{i}$. Transfectants both bound and phagocytosed IgG-sensitized erythrocytes and, following activation of FcrRIIIA, increased $\left[\mathrm{Ca}^{2+}\right]_{i}$. The $\gamma$ subunit was essential both for the surface expression of the receptor and for transduction of the phagocytic signal. Truncation of the $\gamma$ subunit cytoplasmic domain (amino acids 65-80) eliminated phagocytic function. Phorbol ester inhibited phagocytosis in a concentration-dependent manner, but did not affect IgG-sensitized erythrocytes binding, suggesting that a protein kinase $\mathbf{C}$-dependent pathway inhibits phagocytosis. The data indicate that a tyrosine containing cytoplasmic domain within the $\gamma$ subunit is required for phagocytosis by FcrRIIIA. ( $J$. Clin. Invest. 1993. 92:1967-1973.) Key words: receptors • phagocytosis • signaling • immunoglobulin • macrophages
\end{abstract}

\section{Introduction}

Receptors for the Fc portion of IgG are expressed on many cells of hematopoietic lineage. These receptors are important in host defense and in the ingestion of $\operatorname{IgG}$-coated cells $(1,2)$. There are three classes of human $F c \gamma$ receptors (Fc $\gamma$ RI, Fc $\gamma$ RII, and Fc $\gamma$ RIII), distinguished by IgG subclass affinity, cellular distribution, and reactivity with monoclonal antibodies (1). The genes for these receptors have homology in the coding regions for their extracellular domains, but are divergent in their transmembrane and cytoplasmic regions, suggesting functional specificity for the individual receptors. Fc $\gamma$ RIII (CD16), a low affinity $\mathrm{Fc}$ receptor, has two isoforms that are encoded by two highly homologous genes $(3,4)$. Fc $\gamma$ RIIIB is found only on neutrophils as a glycosyl phosphatidylinositol-linked protein (5). Fc $\gamma$ RIIIA is found on NK cells, cultured monocytes and macrophages $(6,7)$. The receptor is a multichain complex composed of a ligand-binding polypeptide, $\alpha$, and a disulfide-linked dimer of an accessory subunit, $\gamma$ or $\zeta$. The $\gamma$ and $\zeta$ subunits

Address correspondence to Dr. Alan D. Schreiber, University of Pennsylvania Cancer Center, 7 Silverstein Building, Philadelphia, PA 19104.

Received for publication 12 February 1992 and in revised form 25 February 1993.

J. Clin. Invest.

(C) The American Society for Clinical Investigation, Inc.

$0021-9738 / 93 / 10 / 1722 / 07 \$ 2.00$

Volume 92, October 1993, 1967-1973 were originally identified as components of other multimeric receptors, the high affinity receptor for $\operatorname{IgE}(\mathrm{Fc} \epsilon \mathrm{RI})^{1}$ and the $\mathrm{T}$ cell receptor (TCR/CD3), respectively (8-10).

Examination of the functions ascribed to the individual $\mathrm{Fc} \gamma$ receptors and their signal transduction pathways has proven difficult due to coexpression of more than one class of receptor on hematopoietic cells that express Fc receptors. Further complexity is added by various isoforms of Fc $\gamma$ RIIIA. The Fc $\gamma$ RIIIA- $\alpha$ polypeptide associates with a dimer of $\gamma \gamma, \zeta \zeta$, or $\gamma \zeta$ that likely interacts with different second messenger pathways and subserve different functions upon immune complex binding ( 1 ).

A previous report indicated that the fibroblast-derived COS-1 cell line possessed the cellular machinery for phagocytic cell function following $\mathrm{Fc}$ receptor (11) and mannose receptor transfection (12). We used COS-1 cells to evaluate the phagocytic function of the Fc $\gamma$ RIIIA complex, composed of an $\alpha$ and a homodimer of $\gamma$. We observed that COS- 1 transfectants phagocytosed IgG-sensitized cells and that the cytoplasmic domain of its $\gamma$ subunit is required. In addition, we undertook studies with a known inducer of protein kinase $C$ (PKC), PMA, to begin to dissect the signaling pathway involved in phagocytosis by this Fc $\gamma$ RIIIA isoform.

\section{Methods}

Cell culture. COS- 1 cells were maintained in DMEM-high glucose (4.5 $\mathrm{mg} / \mathrm{ml})$, glutamine $(25 \mathrm{mg} / \mathrm{ml})$, penicillin $(100 \mathrm{U} / \mathrm{ml})$, streptomycin $(100 \mu \mathrm{g} / \mathrm{ml})$ and $10 \%$ heat-inactivated $\mathrm{FCS}$ at $37^{\circ} \mathrm{C}$ with $5 \% \mathrm{CO}_{2}$. Cells were seeded onto $3.5-\mathrm{cm}$ plates or six-well plates (Falcon Labware, Oxnard, CA ) at a concentration of $3 \times 10^{5}$ cells/well, $24 \mathrm{~h}$ before transfection. The cells reached approximately $80 \%$ confluence for transfection. All tissue culture reagents were obtained from the University of Pennsylvania Tissue Culture Facility.

Construction of recombinant plasmids. The coding sequence of the Fc $\gamma$ RIIIA- $\alpha$ cDNA (kindly provided by Dr. Bice Perussia, Jefferson College of Medicine, Philadelphia, PA) was ligated into the SV40driven eukaryotic expression vector pSVL (Pharmacia LKB, Piscataway, $\mathrm{NJ}$ ) digested with $\mathrm{XbaI}$ and SacI. The cDNA for the murine Fc $\in \mathrm{RI}$ $\gamma$-subunit (kindly provided by Dr. Jean-Pierre Kinet, National Institutes of Health, Bethesda, MD) was expressed from the same vector. Truncation mutants of the $\gamma$ subunit were constructed by using the two-step overlap-extension PCR (13). GAMdel-1, a mutant with the truncation at $\mathrm{Lys}^{80}$, was generated by changing the codon AAG for Lys to TAG for a termination. GAMdel-2, a mutant with the truncation at $\mathrm{Tyr}^{65}$, was generated by changing the codon TAC for Tyr to TAG for a termination.

Transient transfection of COS-1 cells. Cotransfections of cDNAs were carried out with a modified DEAE-dextran method. Briefly, 300,000 COS-1 cells were seeded on $35-\mathrm{mm}$ well plates, $24 \mathrm{~h}$ before transfection. Plates of $70-80 \%$ confluency were washed twice and incubated for $\mathbf{4 0}$ min with DMEM (GIBCO BRL, Grand Island, NY) with-

1. Abbreviations used in this paper: ADCC, antibody-dependent cellular cytotoxicity; EA, IgG opsonized sheep erythrocyte; Fc $\gamma$ R, Fc receptor for IgG; Fc $\epsilon$, Fc receptor for IgE; PI, phagocytic index; PKC, protein kinase $C ; \mathrm{RBC}$, red blood cells. 
out serum before transfection. $4 \mu \mathrm{g}$ of plasmid DNA $(0.5 \mu \mathrm{g} / \mu \mathrm{l})$ was slowly added to $1 \mathrm{ml}$ of a transfection buffer containing Nu medium (DMEM with $10 \%$ NuSerum [Collaborative Biomedical, Bedford, MA]), $1 \mathrm{mg} / \mathrm{ml}$ of DEAE-dextran and $100 \mu \mathrm{M}$ chloroquine. The transfection buffer containing DNA was added to COS-1 cells with incubation for $4 \mathrm{~h}$ at $37^{\circ} \mathrm{C}$. Cells were then shocked with $10 \%$ DMSO in PBS for 2 min, washed twice with DMEM, and grown in Nu medium. Cells were studied $48 \mathrm{~h}$ following transfection.

Antibodies. Anti-Fc $\gamma$ RIII monoclonal antibody 3G8 (14) was isolated from ascites fluid (the 3G8 hybridoma cell line was kindly provided by Dr. J. Unkeless, Mt. Sinai Medical School, New York, NY) using protein A (Affi-Gel Protein A Maps II; Bio-Rad Laboratories, Richmond, CA $)$. The ascites fluid $(1.5 \mathrm{ml})$ was applied to a $5-\mathrm{ml}$ protein A agarose column. The column was washed with $15 \mathrm{vol}$ of binding buffer, and the IgG was eluted according to manufacturer's instructions. The eluted protein was dialyzed against PBS and concentrated to $7 \mathrm{mg} / \mathrm{ml}$.

A
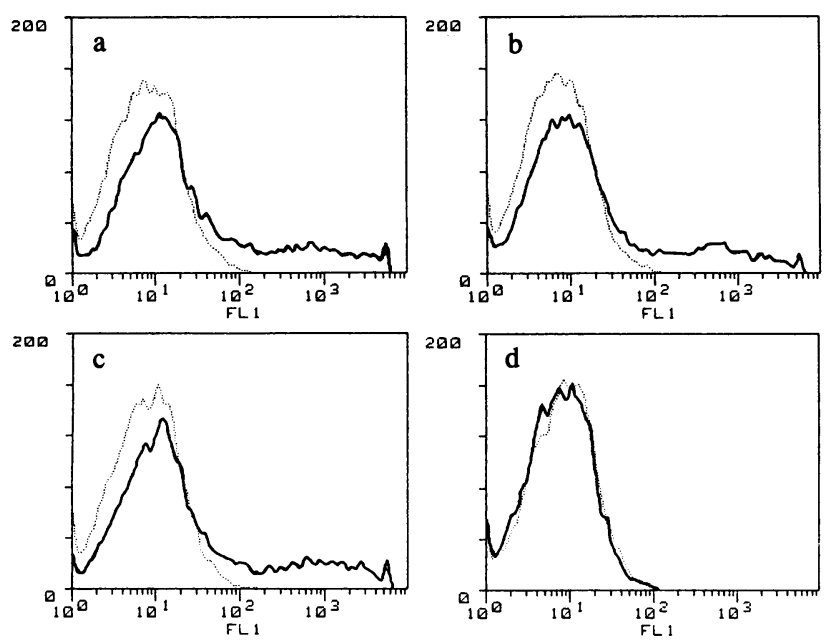

B

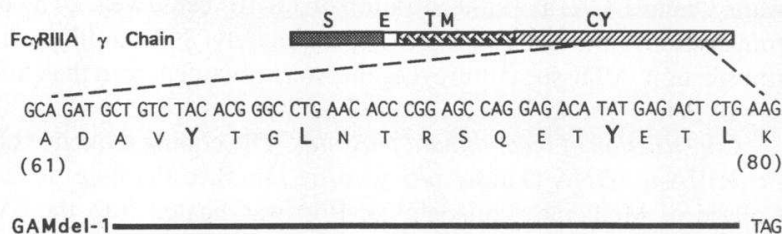

GAMdel-2-TAG

Figure 1. $(A)$ Fluorescence histograms of COS-1 cells expressing Fc $\gamma$ RIIIA- $\alpha$ and $-\gamma$ (wild type and mutants). COS- 1 cells were transfected with Fc $\gamma$ RIIIA- $\alpha$ and $-\gamma$ cDNAs and assayed $48 \mathrm{~h}$ later. The dotted lines represent cells stained with an IgG isotype control P3, while the solid lines represent cells stained with anti-Fc $\gamma$ RIIIA mAb 3G8. Transfection with: ( $a$ ) Fc $\gamma$ RIIIA $\alpha$ and $\gamma$ wild type, (b) Fc $\gamma$ RIIIA $\alpha$ and GAMdel-1, (c) Fc $\gamma$ RIIIA $\alpha$ and GAMdel-2, and (d) Fc $\gamma$ RIIIA- $\alpha$ and pSVL vector DNA without $\gamma$ insert are shown. $(B)$ Schematic representation of $\gamma$ wild type and mutants. Shown with the schematic diagram of the $\gamma$ chain are signal sequence $(S)$, external peptides $(E)$, transmembrane domain $(T M)$, and cytoplasmic domain $(C Y)$. The expanded area shows an area of the nucleotide sequence of the $\gamma$ chain containing a conserved motif. The conserved amino acids are denoted by the bold face. The two thick horizontal bars shown at the bottom of the figure represent $\gamma$ mutants with a termination codon at respective $3^{\prime}$ termini but $5^{\prime}$ ends of the horizontal bars do not represent a termination (their $5^{\prime}$ ends are identical to that of wild type $\gamma$ ).
Table I. Fc $\gamma$ RIIIA Expression and Phagocytosis by COS-1 Cells

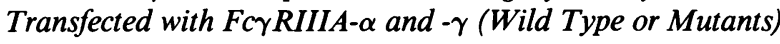

\begin{tabular}{ccccc}
\hline Fc $\gamma$ RIIIA & MFI $^{*}$ & PI $^{\mathbf{s}}$ & Phagocytosis & Rosetting \\
\hline & & & $\%$ Cells + & $\%$ Cells + \\
$\alpha+$ pSVL (Sham) & 15 & 0 & 0 & 0.61 \\
$\alpha+\gamma$ (Wild Type) & 254 & $30 \pm 7.1$ & $8.8 \pm 1.5$ & $36 \pm 3.0$ \\
$\alpha+\gamma$ (GAMdel-1) & 259 & $25 \pm 3.5$ & $6.1 \pm 0.7$ & $35 \pm 1.7$ \\
$\alpha+\gamma$ (GAMdel-2) & 303 & 0 & 0 & $37 \pm 5.2$
\end{tabular}

COS- 1 cells $\left(7 \times 10^{5}\right.$ cells/well) transfected with Fc $\gamma$ RIIIA- $\alpha$ and $-\gamma$ subunit cDNAs were incubated at $37^{\circ} \mathrm{C}$ with EA for $40 \mathrm{~min}$. After Wright-Giemsa staining, phagocytosed RBCs were microscopically scored $(\times 1000)$. Results are expressed as the mean \pm SEM for phagocytic index, phagocytosis, and EA binding (rosetting). At least three separate experiments were performed for each clone. For each experiment, 300 cells were counted at each of three randomly selected sites. Unsensitized RBCs did not bind to transfectants. * MFI, mean fluorescence intensity; ${ }^{8} \mathrm{PI}$, phagocytic index (number of RBCs internalized per 100 COS-1 cells).

Flow cytometry. Anti-Fc $\gamma \mathrm{RIII}$ mAb $3 \mathrm{G} 8$ was used to assess protein expression on the cell surface of transfected COS-1 cells. Cells were gently removed from plates, counted, and resuspended in $50 \mu \mathrm{l}$ staining buffer ( $1 \times$ PBS without $\mathrm{Ca}^{2+} / \mathrm{Mg}^{2+}$, containing $0.02 \%$ sodium azide, $0.1 \%$ BSA) with $5 \mu$ l of primary antibody and placed on ice for $45 \mathrm{~min}$. After two washes, FITC-labeled $F\left(a b^{\prime}\right) 2$ goat anti-mouse IgG (GAM) was added and incubation continued at $4^{\circ} \mathrm{C}$ for $30 \mathrm{~min}$. Isotype controls were used for all reactions. Fluorescence was measured on a FAC$\operatorname{Star}^{\circledR}$ (Becton Dickinson \& Co., Mountain View, CA ). For all samples, 10,000 events were recorded on a $\log$ fluorescence scale and mean fluorescence intensity data and contour maps were generated.

Electron microscopy. COS-1 cells were removed from plates by pipetting and washed to remove media. The pelleted specimens were fixed in $2 \%$ glutaraldehyde in $0.1 \mathrm{M}$ sodium cacodylate buffer, $\mathrm{pH}$ 7.4. After washing three times in $0.1 \mathrm{M}$ cacodylate buffer, $\mathrm{pH} 7.4$, the specimens were fixed in $1 \% \mathrm{OsO}_{4}$ for $30 \mathrm{~min}$ at room temperature. Following dehydration in graded alcohol, the specimens were embedded in Epon-EM-Bed-812 (Electron Microscopy Science, Fort Washington, PA). Thin sections were cut using an LKB Ultratome III microtome (Pharmacia Fine Chemicals, Piscataway, NJ). Pictures were taken with a 300 electron microscope (Philips Electronic Instruments, Inc., Mahwah, NJ).

Preparation of IgG-sensitized red blood cells $(E A)$. Sheep red blood cells $(\mathrm{RBC})$ were sensitized with rabbit anti-sheep $\mathrm{RBC}$ IgG as previously described (14). Briefly, $10^{9}$ sterile sheep RBC (Rockland Inc., Gilbertsville, PA) suspended in $1 \mathrm{ml}$ of calcium- and magnesium-free PBS was sensitized by incubation with an equal volume of PBS containing the highest subagglutinating titer of rabbit anti-sheep RBC antibody (Cappel Laboratories, Cochranville, PA) at $37^{\circ} \mathrm{C}$ for $30 \mathrm{~min}$. The IgG-sensitized sheep RBC (EA) were washed twice with PBS and resuspended in a final concentration of $10^{9} \mathrm{cells} / \mathrm{ml}$ for overlaying on transfected COS- 1 cells.

Binding and phagocytosis of IgG-sensitized RBCs. COS-1 cells were incubated with EA at $37^{\circ} \mathrm{C}$ for $45 \mathrm{~min}$. Unbound EA was removed by extensive washing and stained with Wright-Giemsa to determine the number of cells with bound EA. For the analysis of phagocytosis, COS- 1 cells bound with EA (after three washings) were subjected to a brief hypotonic shock ( $35 \mathrm{~s}$ ) with hypotonic PBS to remove surfacebound EA before staining. Results were expressed as phagocytic index (PI), the number of intracellular EA/100 COS-1 cells. Phagocytosis was also assessed by electron microscopy (with the assistance of Dr. Steven Douglas, Children's Hospital of Philadelphia, PA). Statistical analysis was carried out by one-way analysis of variance and the Stu- 
dent-Newman-Keuls test for comparing means in a multitreatment study using the Primer of Biostatistics (McGraw-Hill, Inc., New York) for the Apple Macintosh Plus.

Effect of PMA on phagocytosis in COS-1 transfectants. PMA (Sigma Chemical Co., St. Louis, MO) was dissolved in DMSO. COS-1 transfectants were incubated with increasing concentrations of PMA for $30 \mathrm{~min}$ followed by incubation with EA for $40 \mathrm{~min}$. COS-1 cells were washed extensively, extracellular EA removed, and the cells analyzed for internalized EA as described above.

Measurement of $\left[\mathrm{Ca}^{2+}\right]_{i}$ following FC $\mathrm{RIIIA}$ activation. $48 \mathrm{~h}$ following transfection with the Fc $\gamma$ RIIIA- $\alpha$ and $\gamma$ cDNAs, cells adherent to 2.5-cm glass cover slips were taken for single-cell measurement of $\left[\mathrm{Ca}^{2+}\right]_{\mathrm{i}}$ following cross-linking of Fc $\gamma$ RIIIA (15). Media were aspirated and replaced by HBSS with Fura-2/AM (Molecular Probes, Inc., Eugene, OR). Cells were incubated for $30 \mathrm{~min}$ at $37^{\circ} \mathrm{C}$, washed, and preincubated for an additional $30 \mathrm{~min}$ with biotinylated anti-Fc $\gamma$ RIII mAb 3G8. The cover slip was transfered to a Leidem cell chamber (Medical Systems, Greenvale, NY) and individual cells were analyzed for a rise in $\left[\mathrm{Ca}^{2+}\right]_{i}$ following delivery by a micropipette of $50 \mu \mathrm{g} / \mathrm{ml}$ streptavidin. Fluorescence was imaged with a 100 Fluor objective and a Diaphot epifluorescence microscope (Nikon Inc., Melville, NY). Emission was collected at $520 \mathrm{~nm}$ by a photomultiplier tube connected to a Johnson Foundation Spinning Wheel Fluorimeter (University of Pennsylvania Biomedical Instrumentation Group, Philadelphia, PA) and digitally analyzed by an IBM AT clone-based system (Indec Systems, Sunnyvale, CA). In control experiments only streptavidin or biotinylated $\mathrm{mAb}$ anti-Fc $\gamma \mathrm{RIII}$ was added to the above cells and mock transfectants.

\section{Results}

Cell-surface expression of transfected Fc $\gamma$ RIIIA. Expression of Fc $\gamma$ RIIIA complexes $48 \mathrm{~h}$ after transfection was determined by flow cytometry using anti-Fc $\gamma$ RIII mAb (Fig. $1 A$ ). Surface expression of the Fc $\gamma$ RIIIA- $\alpha$ protein required interaction with the accessory subunit $\gamma$, as previously noted (16-18). Two deletion mutants of the $\gamma$ chain were constructed by introducing stop codons at amino acids 80 (GAMdel-1 mutant) or 65 (GAMdel-2 mutant) (Fig. $1 B$ ). The cDNAs of these two mutants or wild type $\gamma$ along with the cDNA of $\alpha$ were cotransfected into COS- 1 cells and examined for cell-surface expression of transfected receptor complexes. COS-1 transfectants containing wild type or mutant $\gamma$ exhibited comparable levels of Fc $\gamma$ RIIIA assessed by mean fluorescence intensity and the percentage cells binding EA. Approximately $36 \%$ of the COS- 1 transfectants containing wild type or mutant $\gamma$ avidly bound EA (Table I).

Phagocytosis and binding of EA mediated by FcrRIIIA. We examined COS-1 transfectants containing FcrRIIIA for their ability to bind and phagocytose IgG-sensitized cells. We and others have demonstrated phagocytosis of EA in COS-1 cells and other cell lines derived from fibroblasts, following Fc receptor transfection $(11,19)$. In this study, we employed electron microscopy to examine phagocytosis in COS- 1 cells cotransfected with the Fc $\gamma$ RIIIA $\alpha$ and $\gamma$ subunits. The thin-section electron micrograph demonstrates that COS-1 cells that lack endogenous expression of $\mathrm{Fc}$ receptors are able to phagocytose EA when transfected with Fc $\gamma$ RIIIA (Fig. $2 A$ ). Light microscopic visualization of Wright-Giemsa-stained COS-1 transfectants also revealed phagocytosis of EA. The ingested EA have been found to be enclosed in distinct vesicles, with some RBCs showing partial degradation. Transfectants expressing both the $\alpha$ and $\gamma$ chains showed a substantial degree of EA binding ( $\sim 36 \%$ of cells ) and phagocytosis ( $\sim 9 \%$ of cells )
(Table I, Fig. $2 B$ ). Control transfectants, transfected with Fc $\gamma$ RIIIA- $\alpha$ and pSVL vector without the $\gamma$ chain cDNA, did not exhibit binding of EA ( $<1 \%$ of cells).

Internalization of EA was a time-dependent process and increased significantly from 15 to $60 \mathrm{~min}$ of incubation. There was approximately a fourfold increase in the phagocytic index at $60 \mathrm{~min}$ in comparison to $15 \mathrm{~min}$ (data not shown).

$\gamma$ Chain is essential for phagocytic signal transduction. Although the surface expression of the Fc $\gamma$ RIIIA $\alpha$ chain requires the $\gamma$ chain, it is not known whether $\gamma$ is also involved in the signal transduction events required for phagocytosis. To examine its role in transduction of a phagocytic signal, $\gamma$ wild type or mutants were cotransfected into COS-1 cells along with Fc $\gamma$ RIIIA $\alpha$. The GAMdel- 1 mutant, containing the $\mathrm{COOH}$ terminus 7 amino acid deletion, exhibited a 16\% decrease in phagocytic activity. However, the GAMdel-2 mutant with the $\mathrm{COOH}$ terminus 22 amino acid deletion completely lost its ability to transduce a phagocytic signal (Table I), suggesting that the cytoplasmic region spanning $\mathrm{Tyr}^{65}$ to $\mathrm{Leu}^{79}$ is critical for the phagocytic signal. These results demonstrate that the $\gamma$ chain is essential not only for the surface expression of the $\alpha$ chain but also for the phagocytic function of the receptor.

The effect of PMA on phagocytosis. Previous studies have shown that treatment of PMA increases Fc $\gamma$ RIIA mediated phagocytosis in neutrophils and HEL cells $(20,21)$. In this study, addition of PMA $\left(10^{-6}-10^{-10} \mathrm{M}\right)$ progressively decreased phagocytosis in transfectants expressing Fc $\gamma$ RIIIA, with more than a fivefold decrease observed at $10^{-7} \mathrm{M}$. In contrast, transfectants expressing Fc $\gamma$ RIIA exhibited an increase in phagocytic function at lower concentrations $\left(10^{-10}\right.$ and $10^{-9} \mathrm{M}$ ) followed by a modest decrease at higher concentrations $\left(10^{-8}\right.$ and $\left.10^{-6} \mathrm{M}\right)$ (Table II). The effect of PMA depended upon its presence during EA incubation and was rapidly reversible. This effect of PMA on phagocytosis suggests that Fc $\gamma$ RIIIA and Fc $\gamma$ RIIA may mediate their phagocytic signals through different pathways. PMA had no effect on the percentage of COS- 1 cells binding EA by either receptor.

$\left[\mathrm{Ca}^{2+}\right]_{i}$ stimulation following cross-linking of $\mathrm{FC \gamma}$ RIIIA. To assess changes in $\left[\mathrm{Ca}^{2+}\right]_{i}$, we performed single-cell measurements. Upon cross-linking of Fc $\gamma$ RIIIA with biotinylated antiFc $\gamma$ RIII and streptavidin, $\left[\mathrm{Ca}^{2+}\right]_{i}$ rose immediately to 2.5 - to 7 -fold over baseline in 6 out of 24 cells randomly tested (Fig. $3)$. However, none of 23 mock-transfected cells exhibited an increase of $\left[\mathrm{Ca}^{2+}\right]_{i}$ flux when incubated with biotinylated antiFc $\gamma$ RIII and streptavidin (data not shown). Streptavidin alone

Table II. PMA Effect on Fc $\gamma$ R-mediated Phagocytosis in COS-1 Transfectants

\begin{tabular}{|c|c|c|c|c|c|c|}
\hline & Control & $10^{-10} \mathrm{M}$ & $10^{-9} \mathrm{M}$ & $10^{-8} \mathrm{M}$ & $10^{-7} \mathrm{M}$ & $10^{-6} \mathrm{M}$ \\
\hline Fc $\gamma$ RIIA & $61 \pm 13$ & $88 \pm 19$ & $80 \pm 29$ & $46 \pm 6$ & $47 \pm 11$ & $22 \pm$ \\
\hline Fc $\gamma$ RIIIA & $34 \pm 10$ & $33 \pm 10$ & $20 \pm 6$ & $10 \pm 3$ & $6 \pm 2$ & $1=$ \\
\hline
\end{tabular}

PMA was added to cells 30 min before incubation with EA and was present during EA incubation. EA was allowed to bind to transfectants for $\mathbf{4 0}$ min before staining. Results are expressed as the mean PI \pm SEM, $n=5, P<0.05$. For experiments with Fc $\gamma$ RIIA, $2 \mu \mathrm{g}$ of pSVL containing Fc $\gamma$ RIIA and equal amounts of the vector DNA without insert were transfected into COS-1 cells. For Fc $\gamma$ RIIIA, $2 \mu \mathrm{g}$ each of pSVL containing CDNAs of $\alpha$ and $\gamma$ cDNA were used for cotransfection. 


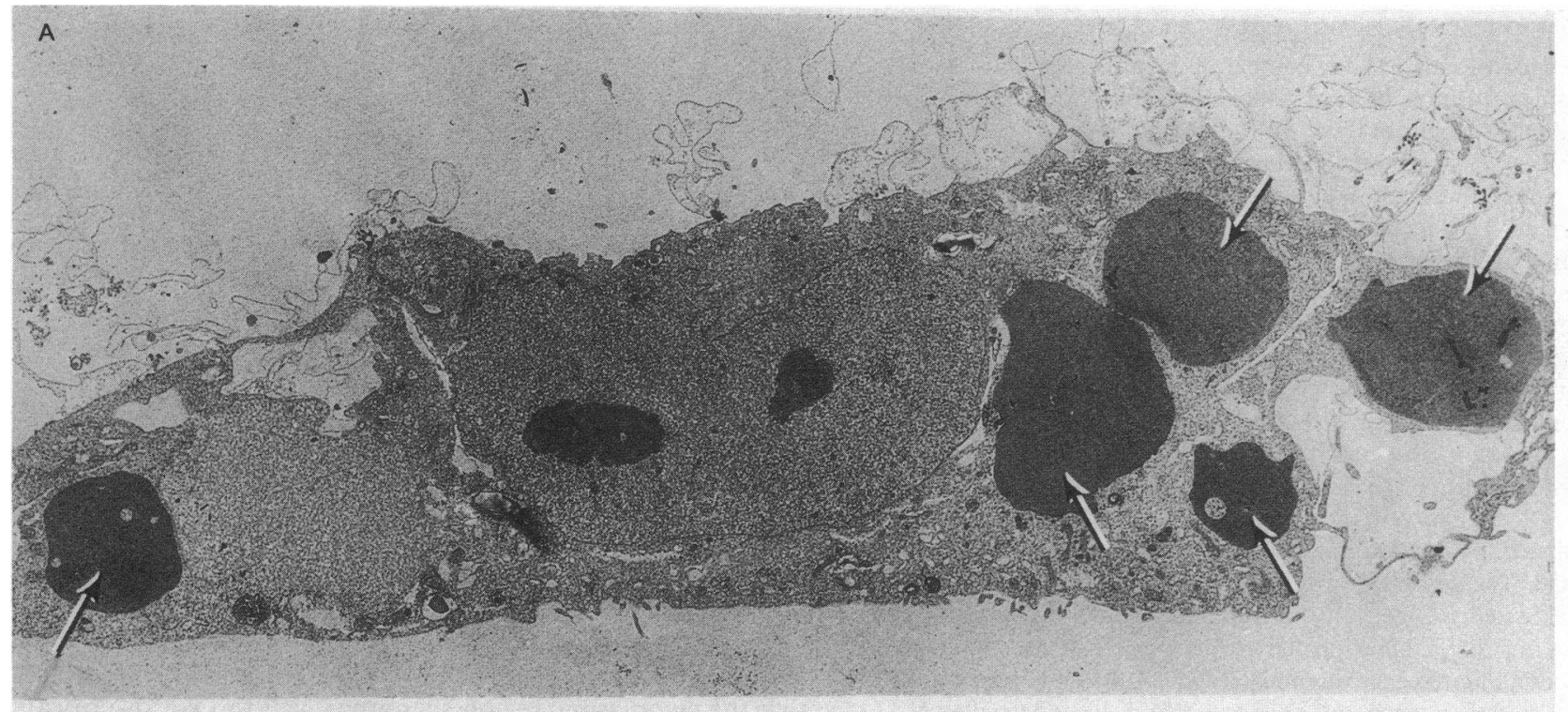

Figure 2. Phagocytosis and EA binding by COS-1 cells expressing Fc $\gamma$ RIIIA. COS- 1 transfectants were incubated with EA for 30 min. Unbound erythrocytes were removed by washing and examined for EA binding. For phagocytic analysis, washed COS-1 cells were treated with a hypotonic solution for $35 \mathrm{~s}$ to remove bound EA. ( $A$ ) Thin-section electron micrograph of COS-1 transfectants demonstrates phagocytosis of EA denoted by arrows. (Picture shows an image magnified by 8000 .) $(B)$ The COS-1 cells were stained with Wright-Giemsa and visualized by a light microscope $(\times 1000)$. (a) Control cells from mock-transfection incubated with EA. (b) EA binding (rosetting) in COS-1 cells expressing Fc $\gamma$ RIIIA. (c) Phagocytosis of EA by COS-1 transfectants.

did not stimulate a rise in $\left[\mathrm{Ca}^{2+}\right]_{\mathrm{i}}$. Epinephrine $(10 \mu \mathrm{M})$, which evokes a $\mathrm{Ca}^{2+}$ signal in $\mathrm{COS}$ cells (22) also stimulated a rise in $\left[\mathrm{Ca}^{2+}\right]_{\mathrm{i}}$ (Fig. 3).

\section{Discussion}

Human Fc $\gamma$ RIIIA is a receptor complex composed of three separate polypeptide chains, the ligand-binding subunit Fc $\gamma$ RIIIA- $\alpha$, and its associated $\gamma$ and $\zeta$ chains found on NK cells, activated monocytes, and macrophages (23). These associated chains belong to a family of polypeptides that dimerize, interact in a noncovalent manner with other polypeptides in multimeric receptors, and are critical for signal transduction by the individual receptors $(24,25)$. The $\gamma$ and $\zeta$ chains are required for surface receptor expression of FceRI and TCR/ CD3, respectively (8-10). It has recently been shown that the $\gamma$ or $\zeta$ subunit significantly increases Fc $\gamma$ RIIIA- $\alpha$ surface expression in cotransfection experiments $(16,18)$. Without the interaction of the $\gamma$ or $\zeta$ molecule, the $\alpha$ chain is targeted for degradation in the endoplasmic reticulum (23). Fc $\gamma$ RIIIA can exist in three molecular forms with the $\alpha$ chain associated with either $\gamma \gamma, \zeta \zeta$, or $\gamma \zeta$. The Fc $\gamma$ RIIIA- $\alpha-\gamma \gamma$ isoform is found in macrophages, while all three forms occur in NK cells that express both the $\gamma$ and $\zeta$ subunits $(26,27)$. We chose to evaluate the role of one specific isoform, Fc $\gamma$ RIIIA- $\alpha-\gamma \gamma$, in signaling following binding of Fc $\gamma$ RIIIA by IgG-coated erythrocytes (EA) or anti-Fc $\gamma$ RIII mAb in a transient transfection system.

Prior studies evaluating individual Fc receptor functions have relied upon the use of cells expressing more than one class of Fc receptor and receptor-specific IgG subclasses or mAbs to simulate ligand binding. Under these conditions, the relative binding specificity, displacement of mAbs by immune complexes, or cooperativity between the cytoplasmic domains of the different $\mathrm{Fc}$ receptor classes may influence the results. Fc receptor-negative COS-1 cells have previously been shown to be an effective transfection system for evaluating mannose receptor (12) and for individual Fc receptor function $(11,19)$. Thus, analysis of Fc receptor signaling in this system can occur without the potential interpretation that the cytoplasmic domains of different receptors interact following ligand binding. Our results obtained with thin-section electron microscopy further demonstrate that COS- 1 cells are an attractive model system to study the phagocytic signal transduction pathway.

COS- 1 cells cotransfected with $\alpha$ and $\gamma$ (wild type and mutants) subunits of Fc $\gamma$ IIIA demonstrated comparable levels of cell-surface expression of the multimeric Fc $\gamma$ RIIIA (Table I). Transfection of cells with Fc $\gamma$ RIIIA- $\alpha$ chain alone did not induce its cell-surface expression. Thus, our data indicate that the $\gamma$ chain is necessary for both the surface expression of Fc $\gamma$ RIIIA and its transmission of a phagocytic signal. During the preparation of our manuscript, it was shown by others that the $\gamma$ subunit of Fc $\gamma$ RIIIA plays a critical role in antigen presentation in transformed B cells (28) and in $\mathrm{Ca}^{2+}$ signaling in transfected $\mathrm{T}$ and mast cells (29). Our results further demonstrate that the $\gamma$ subunit of Fc $\gamma$ RIIIA is essential for the signal transduction ability of this receptor. It is of note that the region deleted in the GAMdel-2 mutant contains two conserved tyrosines and leucines present in several signaling molecules of the immunoglobulin gene superfamily $(30,31)$.

An increase in $\left[\mathrm{Ca}^{2+}\right]_{\mathrm{i}}$ was demonstrated with COS-1 cells expressing wild type Fc $\gamma$ RIIIA $\alpha$ and $\gamma$ following receptor cross-linking, suggesting that the Fc $\gamma$ RIIIA- $\alpha-\gamma \gamma$ isoform can initiate events involved in $\mathrm{Ca}^{2+}$ mobilization. The cytoplasmic domain required for a phagocytic signal, described above, also appears to play an important role for intracellular $\mathrm{Ca}^{2+}$ mobilization, as mutants of the $\gamma$ chain in which tyrosine was replaced by phenylalanine exhibited significant reductions in intracellular $\mathrm{Ca}^{2+}$ mobilization (31a). Intracellular $\mathrm{Ca}^{2+}$ increases have been demonstrated for all three $\mathrm{Fc} \gamma$ receptor classes $(2,32,33)$. Similarly, it has been observed that both 

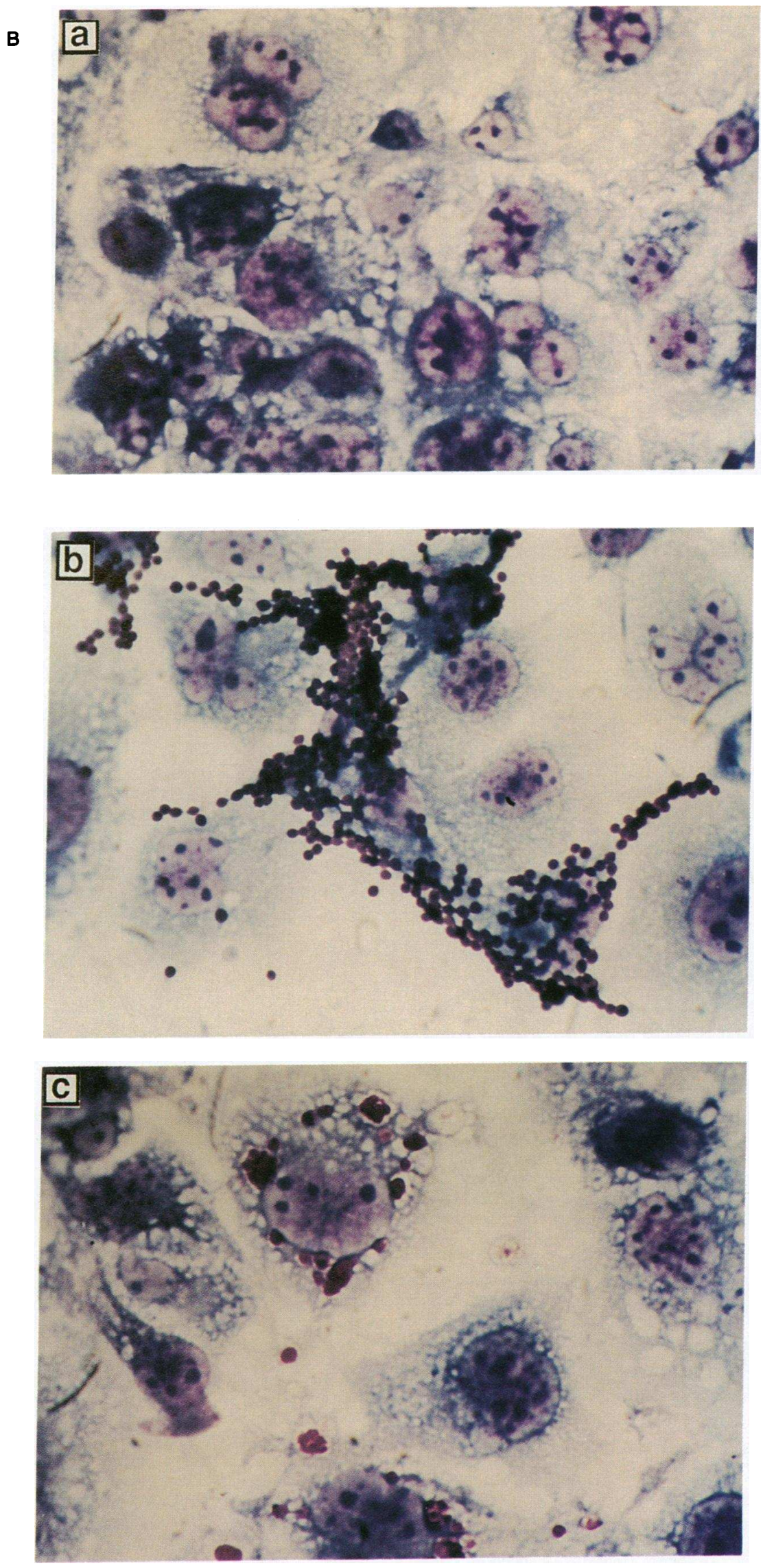


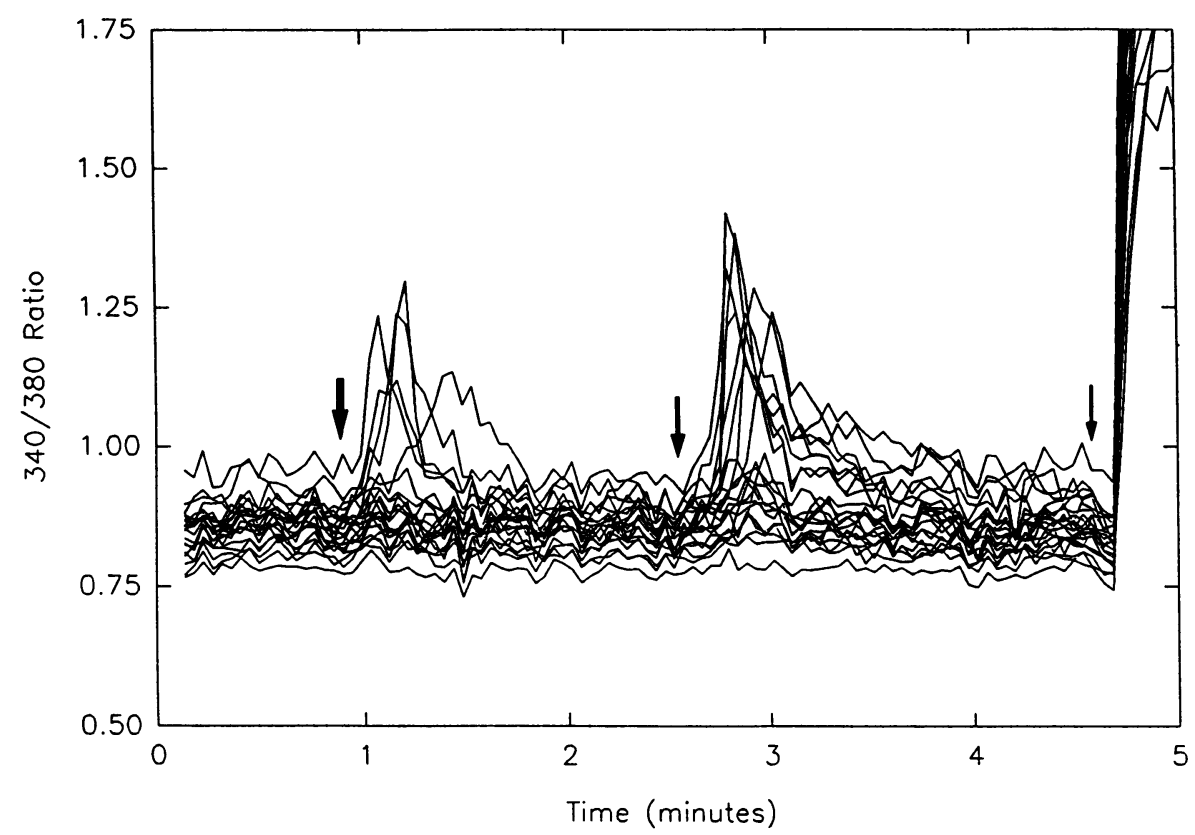

Figure 3. $\left[\mathrm{Ca}^{2+}\right]_{\mathrm{i}}$ increase on a single cell level following cross-linking of Fc $\gamma$ RIIIA. COS-1 transfectants plated on glass coverslips were loaded with Fura-2/AM. After obtaining baseline $\left[\mathrm{Ca}^{2+}\right]_{i}$, bound biotinylated anti-Fc $\gamma$ RIII was cross-linked by the addition of streptavidin. In control experiments, only streptavidin or biotinylated anti-Fc $\gamma$ RIII was added with no increase in $\left[\mathrm{Ca}^{2+}\right]_{i}$ over baseline. The arrows from left to right (the thickest to the thinnest) represent three time points when streptavidin (following preincubation with biotinylated anti-Fc $\gamma$ RIII), epinephrine, and ionomycin are added, respectively.
TCR/CD3 isoforms, $\mathrm{CD} 3 \zeta$ and $\mathrm{CD} 3 \eta$, also transmit signals responsible for $\mathrm{Ca}^{2+}$ mobilization (24).

The Fc $\gamma$ RIIIA- $\alpha-\gamma \gamma$ isoform mediated both binding and phagocytosis of IgG-sensitized erythrocytes in COS-1 transfectants without the presence of other Fc receptors. Since Fc $\gamma$ RIIIA is an abundant $F c \gamma$ receptor on macrophages and the $\gamma$ chain is the only member of its family expressed in these cells, these experiments suggest that the Fc $\gamma$ RIIIA- $\alpha-\gamma \gamma$ isoform in macrophages plays an important role in phagocytosis. This process may involve increases in intracellular $\mathrm{Ca}^{2+}(34)$. In NK cells, different $\mathrm{Fc} \gamma \mathrm{RIIIA}$ signaling pathways involved in ADCC and NK-cell activation may be mediated by $\gamma \zeta$ or $\zeta \zeta$ isoforms.

Through stimulation of the second messenger pathway involving PKC, PMA can affect events in the phagocytic process $(20,21)$. We evaluated the effects of PMA on phagocytosis in COS- 1 transfectants expressing either Fc $\gamma$ RIIIA or Fc $\gamma$ RIIA. PMA $\left(10^{-7} \mathrm{M}\right)$ has been known to elicit superoxide anion production in U937 cells (35) and to stimulate both complement receptor-mediated phagocytosis in cultured monocytes (36) and Fc $\gamma$ RII-mediated phagocytosis in neutrophils and HEL cells $(20,21)$. However, the same concentration of PMA $\left(10^{-7} \mathrm{M}\right)$ caused an $82 \%$ reduction of phagocytosis in COS-1 transfectants expressing Fc $\gamma$ RIIIA, while phagocytosis was reduced only by $13 \%$ in Fc $\gamma$ RIIA transfected cells. That Fc $\gamma$ RIIA transfectants consistently show moderate increases at $10^{-10}$ $10^{-9} \mathrm{M}$ of PMA suggests that there are differences between these two Fc $\gamma$ receptors in intracellular signaling. These receptors may mediate phagocytosis in macrophages and stimulate monocytes by coupling with different second messenger pathways. PKC upregulation may be able to stimulate the Fc $\gamma$ RIImediated pathway, while inhibiting phagocytosis by Fc $\gamma$ RIIIA.

We have used a model system to study the role of individual Fc receptors, in transmission of a phagocytic signal. We observed that macrophage Fc $\gamma$ RIIIA is able to mediate phagocytosis and that the $\gamma$ subunit of the receptor is essential both for surface expression and for signal transduction mediated by the receptor following activation. Future studies will examine the role of different isomers of Fc $\gamma$ RIIIA and map the area and individual amino acids critical for transmission of the phagocytic signal.

\section{Acknowledgments}

The authors wish to thank Dr. John Williamson (University of Pennsylvania) for the use of his Leidem cell chamber and fluorescent microscope/computerized analysis system for evaluation of calcium signaling. EM work was made possible by Mr. Natali Thomassini and Dr. Steven Douglas (Children's Hospital of Philadelphia, PA).

This work was supported by National Institutes of Health grants AI-22193 and HL-27068.

\section{References}

1. Ravetch, J. V., and J.-P. Kinet. 1991. Fc Receptors. Annu. Rev. Immunol. 9:457-492.

2. van de Winkel, J. G. J., and C. L. Anderson. 1991. Biology of human immunoglobulin G Fc receptors. J. Leukocyte Biol. 49:511-524.

3. Qui, W. Q., D. De Bruin, B. H. Brownstein, R. Pearse, and J. V. Ravetch. 1990. Organization of the human and mouse low-affinity $F c \gamma R$ genes: duplication and recombination. Science (Wash. DC). 248:732-735.

4. Ravetch, J. V., and B. Perussia. 1989. Alternative membrane forms of Fc $\gamma$ RIII (CD16) on human NK cells and neutrophils: Cell-type specific expression of two genes which differ in single nucleotide substitutions. J. Exp. Med. 170:481-497.

5. Selvaraj, P., W. F. Rosse, R. Silber, and T. A. Springer. 1988. The major Fc receptor in blood has a phosphatidylinositol anchor and is deficient in paroxysmal nocturnal haemoglobinuria. Nature (Lond.) 333:565-567.

6. Darby, C., P. Chien, M. D. Rossman, and A. D. Schreiber. 1990. Monocyte/macrophage Fc $\gamma$ RIII, unlike Fc $\gamma$ RIII on neutrophils, is not a phosphatylinositol-linked protein. Blood. 75:2396-2400.

7. Perussia, B., and J. V. Ravetch. 1991. Fc $\gamma$ RIII (CD16) on human macrophages is a functional product of the Fc $\gamma$ RIII-2 gene. Eur. J. Immunol. 21:425429.

8. Ra, C., M.-H. E. Jouvin, and J.-P. Kinet. 1989. Complete structure of the mouse mast cell receptor for $\mathrm{IgE}(\mathrm{Fc} \in \mathrm{RI})$ and surface expression of chimeric receptors (rat-mouse-human) on transfected cells. J. Biol. Chem. 264:1532315327.

9. Kuster, H., H. Thompson, and J. P. Kinet. 1990. Characterization and expression of the gene for the human Fc receptor $\gamma$ subunit. J. Biol. Chem. 265:6448-6452.

10. Weiss, A. 1990. Structure and function of the T cell antigen receptor. $J$ Clin. Invest. 86:1015-1022. 
11. Indik, Z., C. Kelly, P. Chien, A. I. Levinson, and A. D. Schreiber. 1991. Human Fc $\gamma$ RII, in the absence of other Fc $\gamma$ receptors, mediates a phagocytic signal. J. Clin. Invest. 88:1766-1771.

12. Kruskal, B. A., K. Sastry, A. B. Warner, C. E. Mathieu, and R. A. B. Ezekowitz. 1992. Phagocytic chimeric receptors require both transmembrane and cytoplasmic domains from the mannose receptor. J. Exp. Med. 176:16731680.

13. Horton, R. M., Z. Cai, S. N. Ho, and L. R. Pease. 1990. Gene splicing by overlap extension: tailor-made genes using the polymerase chain reaction. Bio techniques. 8:528-535.

14. Schreiber, A. D., J. Parsons, P. McDermott, and R. A. Cooper. 1975 Effect of corticosteroids on the human monocyte IgG and complement receptors. J. Clin. Invest. 56:1189-1197.

15. Fleit, H. B., S. D. Wright, and J. C. Unkeless. 1982. Human neutrophil Fc receptor distribution and structure. Proc. Natl. Acad. Sci. USA. 79:3275-3279.

16. Kurosaki, T., and J. V. Ravetch. 1989. A single amino acid in the glycosyl phosphatidylinositol attachment domain determines the membrane topology of FcyRIII. Nature (Lond.). 342:805-807.

17. Hibbs, M. L., P. Selvaraj, O. Carpen, T. A. Springer, H. Kuster, M.-H. E. Jouvin, and J.-P. Kinet. 1989. Mechanisms for regulating expression of membrane isoforms of Fc $\gamma$ RIII (CD16). Science (Wash. DC). 246:1608-1611.

18. Lanier, L. L., G. Yu, and J. P. Phillips. 1989. Co-assocation of CD3 $\zeta$ with a receptor (CD16) for IgG Fc on human NK cells. Nature (Lond.). 342:803-805.

19. Tuijman, W. B., P. J. A. Capel, and J. G. J. van de Winkel. 1992. Human low-affinity IgG receptor Fc $\gamma$ RIIa (CD32) introduced into mouse fibroblasts mediates phagocytosis of sensitized erythrocytes. Blood. 79:1651-1656.

20. Rosales, C., and E. J. Brown. 1991. Two mechanisms for IgG Fc-receptormediated phagocytosis by human neutrophils. J. Immunol. 146:3937-3944.

21. Kelly, C. J., Z. K. Indik, R. Isaacs, P. Chien, J. M. Daly, and A. D. Schreiber. 1991. The human platelet/megakaryocyte $\mathrm{Fc} \gamma$ receptor (Fc $\gamma \mathrm{RII}$ ) mediates a phagocytic signal which is enhanced by phorbol ester activation. Blood. 78:393a.

22. McGillis, J. P., J. Sudduth-Klinger, G. Harrowe, M. Mitsuhashi, and D. G. Payan. 1989. Transient expression of the angiotensin II receptor: a rapid and functional analysis of a calcium-mobilizing seven transmembrane domain receptor in COS-7 cells. Biochem. Biophys. Res. Commun. 165:935-941.

23. Kurosaki, T., I. Gander, and J. V. Ravetch. 1991. A subunit common to an IgG Fc receptor and the T-cell receptor mediates assembly through different interactions. Proc. Natl. Acad. Sci. USA. 88:3837-3840.

24. Irving, B. A., and A. Weiss. 1991. The cytoplasmic domain of the T cell receptor $\zeta$ chain is sufficient to couple to receptor-associated signal transduction pathways. Cell. 64:891-901.
25. Bauer, A., D. J. McConkey, F. D. Howard, L. K. Clayton, D. Novick, S. Koyasu, and E. L. Reinherz. 1991. Differential signal transduction via T-cell receptor $\mathrm{CD} 3 \zeta_{2}, \mathrm{CD} 3 \zeta-\eta$, and $\mathrm{CD} 3 \eta_{2}$ isoforms. Proc. Natl. Acad. Sci. USA. 88:3842-3846.

26. Ra, C., M.-H. E. Jouvin, U. Blank, and J.-P. Kinet. 1989. A macrophage $\mathrm{Fc} \gamma$ receptor and the mast cell receptor for immunoglobulin $\mathrm{E}$ share an identical subunit. Nature (Lond.). 341:752-754.

27. Anderson, P., M. Caligiuri, C. O'Brian, T. Manley, J. Ritz, and S. F. Schlossman. 1990. Fc $\gamma$ RIII (CD16) is included in the $\zeta$ NK receptor complex expressed by human natural killer cells. Proc. Natl. Acad. Sci. USA. 87:22742278.

28. Amigorena, S., J. Salamero, J. Davoust, W. H. Fridman, and C. Bonnerot. 1992. Tyrosine-containing motif that transduces cell activation signals also determines internalization and antigen presentation via type III receptor for IgG. Nature (Lond.). 358:337-341.

29. Wirthmueller, U., T. Kurosaki, M. S. Murakami, and J. V. Ravetch. 1992. Signal transduction by Fc $\gamma$ RIII (CD16) is mediated through the $\gamma$ chain. $J$. Exp. Med. 175:1381-1390.

30. Reth, M. 1989. Antigen receptor tail clue. Nature (Lond.). 338:383-384.

31. Huang, M.-M., Z. Indik, L. F. Brass, J. A. Hoxie, A. D. Schreiber, and J. S. Brugge. 1992. Activation of $\mathrm{Fc} \gamma \mathrm{RII}$ induces tyrosine phosphorylation of multiple protein including Fc $\gamma$ RII. J. Biol. Chem. 267:5467-5473.

31 a.Park, J.-G., R. K. Murray, P. Chien, C. Darby, and A. D. Schreiber. 1993. Conserved cytoplasmic tyrosine residues of the $\gamma$ subunit are required for a phagocytic signal mediated by Fc $\gamma$ RIIIA. J. Clin. Invest. 92:2073-2079.

32. Cassatella, M. A., I. Anegon, M. C. Cuturi, P. Griskey, G. Trinchieri, and B. Perussia. 1989. Fc $\gamma \mathrm{R}(\mathrm{CD} 16)$ interaction with ligand induces $\mathrm{Ca}^{2+}$ mobilization and phosphoinositide turnover in human natural killer cells. J. Exp. Med 169:549-567.

33. Odin, J., J. C. Edberg, C. J. Painter, R. P. Kimberly, and J. C. Unkeless. 1991. Regulation of phagocytosis and $\left(\mathrm{Ca}^{2+}\right)_{i}$ flux by distinct regions of an $\mathrm{Fc}$ receptor. Science (Wash. DC). 254:1785-1788.

34. Collart, M. A., D. Belin, C. Briottet, B. Thorens, J.-D. Vassalli, and P. Vassalli. 1989. Receptor-mediated phagocytosis by macrophages induces a calcium-dependent transient increase in c-fos transcription. Oncogene. 4:237-241.

35. Laskin, D. L., A. J. Beavis, A. A. Sirak, S. M. O’Connell, and J. D. Laskin 1990. Differentiation of U-937 histiocytic lymphoma cells towards mature neutrophilic granulocytes by dibutyryl cyclic adenosine-3',5'-monophosphate. Cancer Res. 50:20-25.

36. Wright, S. D., and S. C. Silverstein. 1982. Tumor-promoting phorbol esters stimulate $\mathrm{C} 3 \mathrm{~b}$ and $\mathrm{C} 3 \mathrm{~b}^{\prime}$ receptor-mediated phagocytosis in cultured human monocytes. J. Exp. Med. 156:1149-1164. 